\title{
Emphysematous Cystitis with Diabetic Neurogenic Bladder
}

\author{
Kazuya Yoshida ${ }^{1}$, Koji Murao ${ }^{2}$, Nobuo Fukuda ${ }^{1}$, Yoshiyuki Tamura ${ }^{1}$ and Toshihiko Ishida ${ }^{2}$
}

\begin{abstract}
A 62-year-old diabetic woman suffering from high fever was admitted to our hospital. She had a lower abdominal phantom tumor and hyperglycemia. The results of urine analysis showed hematuria and bacteriuria. $\mathrm{X}$-ray and computed tomography revealed gas accumulation in the wall of the bladder. Escherichia coli was identified in urine culture. On the basis of the lack of urine output and the identification of residual urine on catheterization, a diagnosis of emphysematous cystitis with diabetic neurogenic bladder was established. The patient recovered after discontinuation of urinary drainage, intensive insulin therapy, and antibiotic therapy.
\end{abstract}

Key words: emphysematous cystitis, diabetes mellitus, neurogenic bladder, urinary tract infections

(Inter Med 49: 1879-1883, 2010)

(DOI: 10.2169/internalmedicine.49.3247)

\section{Introduction}

Emphysematous cystitis is a comparatively rare urinary tract infection. Acute bacterial cystitis in patients with diabetes mellitus (1), various neurogenic bladder diseases, and recurrent urinary tract infection may be associated with the formation of both intraluminal and intramural gas in the urinary bladder (2). Only approximately 60 such cases have been reported in Japan. Associated diabetes has been noted in about $62 \%$ of these reported cases (3). Since the present case of emphysematous cystitis is accompanied by untreated diabetic neurogenic bladder, we will also discuss cases from the literature.

\section{Case Report}

In mid-October 2008, a 62-year-old woman was admitted to our hospital because of general fatigue, anorexia, and gait disturbance for the preceding $5 \mathrm{~d}$. During the initial physical examination, the patient was not in acute distress. She was febrile with a temperature of $39.0^{\circ} \mathrm{C}$. Her pulse was regular at a rate of 74 beats $/ \mathrm{min}$, blood pressure was $158 / 92 \mathrm{~mm}$ $\mathrm{Hg}$, respiratory rate was $22 / \mathrm{min}$, and arterial oxygen saturation estimated by pulse oximetry was $98 \%$. The lungs were clear to auscultation, and heart sounds were normal with no murmurs. The lower abdomen was distended up to the um- bilicus with mild suprapubic tenderness and tympanic percussion sounds. There were no peritoneal signs and bowel sounds were normal. The chest X-ray and the electrocardiogram obtained at the time of admission were normal. The following were the findings of tests (Table 1) performed at the time of admission: white blood cell (WBC) count, 18,380 cells $/ \mu \mathrm{L}$; and C-reactive protein (CRP) level, 25.5 $\mathrm{mg} / \mathrm{dL}$. Urinary tract infection was suspected from the finding of proteinuria, elevated WBC count, microhematuria, and hyperglycemia control [hemoglobin Alc (HbA1c): 12.1\%]. Escherichia coli was identified in urine culture. Duplicate blood cultures were negative. Plain radiography and computed tomography of the pelvis indicated gas accumulation within the bladder wall and the bladder lumen with an air-fluid level indicative of emphysematous cystitis (Figs.1 and 2). It was therefore necessary to repeat the urinary drainage and intravenous administration of imipenem/ cilastatin $(2 \mathrm{~g} / \mathrm{d})$ for $8 \mathrm{~d}$, pazufloxacin mesilate $(1 \mathrm{~g} / \mathrm{d})$ for 8 $\mathrm{d}$, and internal administration of levofloxacin for $14 \mathrm{~d}$. Hyperglycemia was eventually controlled by continuous intravenous insulin administration followed by a shift to intensive insulin therapy after the third day. At this stage, recovery was slow. Reduction in E. coli count required $30 \mathrm{~d}$ of treatment. During follow-up, computed tomography of the pelvis indicate only slight intramural gas in the bladder. Autonomic failure was observed using a sensitive marker. The values for the coefficient of variation of R-R intervals

${ }^{1}$ Department of Internal Medicine and Clinical Research, National Hospital Organization, Zentsuji National Hospital, Kagawa and ${ }^{2}$ Division of Endocrinology and Metabolism, Department of Internal Medicine, Faculty of Medicine, Kagawa University, Kagawa

Received for publication December 11, 2009; Accepted for publication June 3, 2010

Correspondence to Dr. Kazuya Yoshida, kyoshida@jun.ncvc.go.jp 
Table 1. Laboratory Data upon Admission

\begin{tabular}{|c|c|}
\hline \multicolumn{2}{|l|}{ Urinalysis } \\
\hline PH (5.0 8.0) & 5.50 \\
\hline Protein (-) & $\underline{300 \mathrm{mg} / \mathrm{dL}}$ \\
\hline Occult blood (-) & $1-4 / \mathrm{HPF}$ \\
\hline WBC (-) & $5-9 / \mathrm{HPF}$ \\
\hline Ketone body (-) & - \\
\hline \multicolumn{2}{|l|}{$\mathrm{CBC}$} \\
\hline WBC (3600 9600) & $18380 / \mu \mathrm{L}$ \\
\hline RBC (376 500) & $37 \overline{32 \times 10^{4} / \mu \mathrm{L}}$ \\
\hline $\mathrm{Hb}(11.3 \sim 15.2)$ & $11.0 \mathrm{mg} / \mathrm{dL}$ \\
\hline Ht (33 45) & $\underline{32.2 \%}$ \\
\hline Platelet (13.0 36.9) & $22.9 \times \overline{10^{4} / \mu \mathrm{L}}$ \\
\hline \multicolumn{2}{|l|}{ Serological test } \\
\hline $\mathrm{CRP}(<0.3)$ & $25.5 \mathrm{mg} / \mathrm{dL}$ \\
\hline \multicolumn{2}{|l|}{ Blood Chemisitry } \\
\hline AST (aspartate aminotransferase) (13 33) & $13 \mathrm{IU} / \mathrm{L}$ \\
\hline ALT (alanine aminotransferase ) (6 27) & $14 \mathrm{IU} / \mathrm{L}$ \\
\hline LDH (lactate dehydrogenase) (119 229) & $293 \mathrm{IU} / \mathrm{L}$ \\
\hline Total bilirubin $(0.3 \sim 1.2)$ & $0.3 \mathrm{mg} / \mathrm{dL}$ \\
\hline Total protein $(6.7 \sim 8.3)$ & $4.6 \mathrm{~g} / \mathrm{dL}$ \\
\hline BUN (8 22) & $28.0 \mathrm{mg} / \mathrm{dL}$ \\
\hline $\mathrm{Cr}(0.4 \sim 0.7)$ & $0.9 \mathrm{mg} / \mathrm{dL}$ \\
\hline Sodium (138 146) & $127 \mathrm{mEq} / \mathrm{L}$ \\
\hline Potassium (3.6 4.9) & $\underline{6.3 \mathrm{mEq} / \mathrm{L}}$ \\
\hline Chlorine (99 109) & $89 \mathrm{mEq} / \mathrm{L}$ \\
\hline Glucose (80 112) & $472 \mathrm{mg} / \mathrm{dL}$ \\
\hline HbAlc $(<5.8)$ & $12.1 \%$ \\
\hline \multicolumn{2}{|l|}{ Blood gas analysis } \\
\hline $\mathrm{pH}$ & $\underline{7.462}$ \\
\hline $\mathrm{pO}_{2}$ & $71.7 \overline{\mathrm{mmHg}}$ \\
\hline $\mathrm{PaCO}_{2}$ & $33.0 \mathrm{mmHg}$ \\
\hline $\mathrm{HCO}_{3}^{-}$ & $23.6 \mathrm{mmol} / \mathrm{L}$ \\
\hline Base excess & $1.2 \mathrm{mmol} / \mathrm{L}$ \\
\hline \multicolumn{2}{|l|}{ Neurological study } \\
\hline $\begin{array}{l}\text { CVR-R (coefficient of variation of R-R } \\
\text { intervals in electrocardiogram) }(>2.00)\end{array}$ & $\underline{0.67 \%}$ \\
\hline Vibration (> 10) & $\underline{3 \mathrm{sec}}$ \\
\hline
\end{tabular}

The underlines indicate abnormal data.

in electrocardiogram (CVR-R) and vibration were clearly abnormal. Moreover, with no urine output and residual urine recognized on catheterization, neurogenic bladder was diagnosed. The patient was allowed to leave the hospital on the 37th hospital day (Fig. 3).

\section{Discussion}

Emphysematous cystitis is a relatively rare disease with only 63 cases (Table 2) having been reported in Japan. About $65 \%$ of these reports identified diabetes as the basic disorder complicated by lower urinary tract obstructions or other conditions such as neurogenic bladder $(4,5)$. Bacterial fermentation of glucose causes the formation of carbon dioxide gas bubbles $(6,7)$. The risk factors of the disease include (i) advanced age, particularly for woman, (ii) diabetes mellitus, (iii) neurogenic bladder, (iv) urethral catheter placement, (v) vesicorectal fistula, (vi) end-stage renal disease, and (vii) outlet obstruction (8). The present case indicated three of these factors (advanced age, diabetes mellitus, and neurogenic bladder). We expect that the discrepancy between high fever $\left(39.0^{\circ} \mathrm{C}\right)$ and normal heart rate (74 beats/ min) might be caused by diabetic autonomic neuropathy. In patients with diabetes mellitus who develop autonomic neuropathy, reduced heart rate variability is quite common (9).

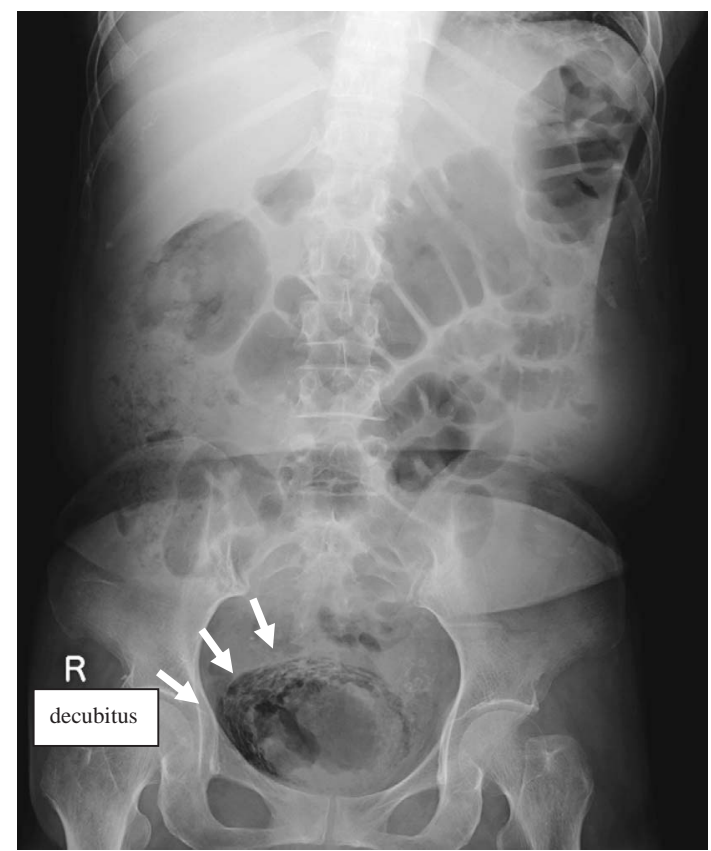

Figure 1. Abdominal X-ray photo of decubitus view suggests the presence of giant gas bubbles within the pelvis (white arrow).

The principal mechanism involved in the generation of gas inside the urinary bladder leading to emphysematous cystitis includes the following: (i) infection by anaerobes, resulting in the generation of gas; (ii) the excretion of fermentation materials such as sugars, protein, etc in the urine; (iii) reduction in local blood flow, resulting in malabsorption of gas due to increased pressure inside the urinary bladder and lower urinary tract disorder; and (iv) decrease in the immune resistance of the host (10). We believe that the present case was caused by a combination of factors such as the existence of sugar in the urine, neurogenic bladder, vascular disorder, and decrease in the immune resistance due to poorly controlled diabetes for a long period of time. The most commonly reported organism is E. coli, as seen in this patient. Other pathogens known to be associated with this condition include Aerobacter aerogenes, Staphylococcus aureus, Klebsiella pneumoniae, Clostridium perfringens, Proteus mirabilis, Nocardia species, and Candida albicans $(11,12)$. Aerobic and anaerobic cultures are required for identification of the etiologic agents.

The clinical symptoms of dysuria, which include increased urinary frequency, fever, abdominal pain, and hematuria, are common in emphysematous cystitis, but the diagnosis is difficult because such symptoms are usually mild and nonspecific, especially in diabetic patients with neurogenic bladder (13). A history of pneumaturia is also highly suggestive, but patients rarely report this symptom (14). The diagnosis is provided by radiographic imaging. An obvious radiographic clue is provided by observation of small pockets of gas in the mucous membrane of the bladder. Other possible causes for the presence of air in the bladder, including fistulous connections with the intestine or vagina after 
(A)

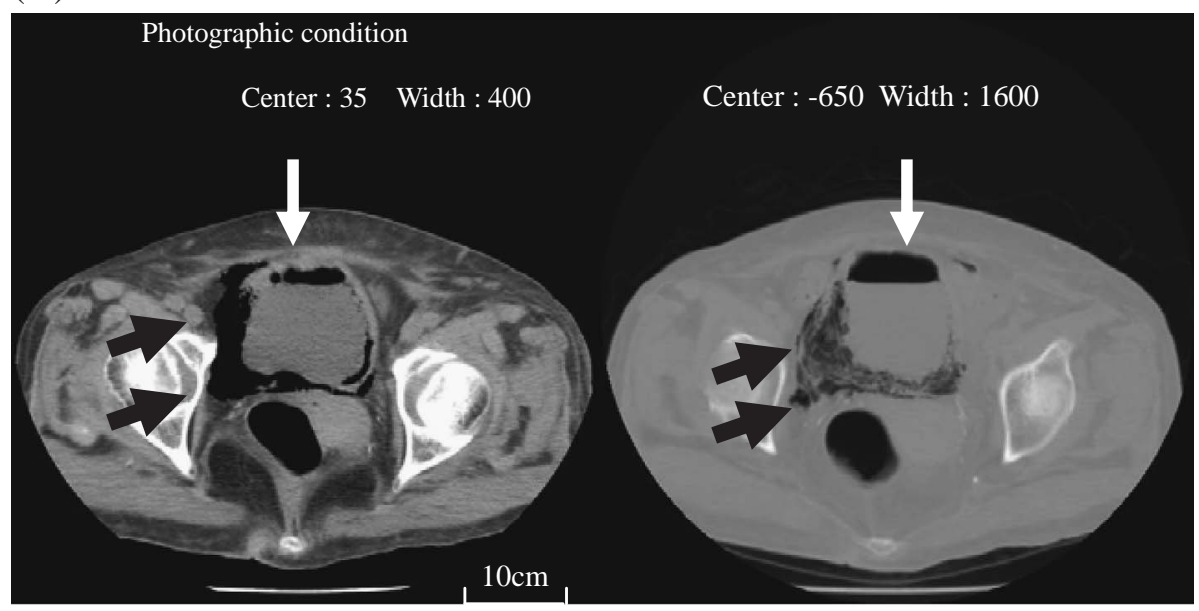

(B)

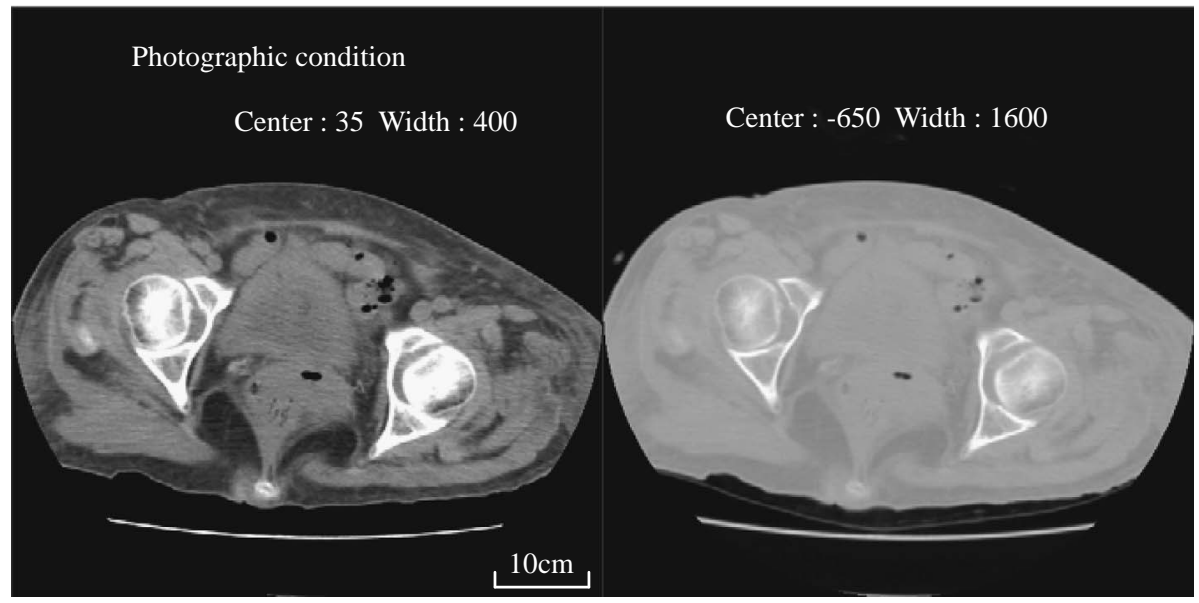

Figure 2. A computed tomographic scan of the pelvis showing emphysematous cystitis. (A) A computed tomographic scan of the pelvis shows a diffuse collection of gas within the bladder wall (black arrows) and the bladder lumen (white arrow). (B) A computed tomographic scan after complete treatment.

trauma or surgery, must be excluded to ensure a proper diagnosis (15). In the present case, the gas accumulation was observed both in the bladder wall and the urinary bladder in the absence of a history of pneumaturia. Gas within the urinary tract was first described in 1671 in a man presenting with pneumaturia (16). Air within the bladder wall has also been discovered during human and animal autopsy, and the condition was later defined by Bailey in 1961 as "cystitis emphysematosa" $(17,18)$. Diabetes mellitus affects the urinary tract and increases the risk of diabetic nephropathy, renal papillary necrosis, renal artery stenosis, and bladder dysfunction secondary to neuropathy. These conditions combined with glycosuria and impaired leukocyte infection increase the risk of a diabetic patient acquiring complicated urinary tract infections such as emphysematous cystitis (19). The incidence of urinary tract infection is three-fold higher in diabetic women than in non-diabetic women (19). Previous reviews stated that half of the patients with emphysematous cystitis had diabetes mellitus, with a 2:1 female to male predominance $(17,19-21)$. About $65 \%$ identified diabetes as the basic disorder and about $62 \%$ were women in 63 cases of emphysematous cystitis in the Japanese literature (Table 2). This suggests that diabetic patients, particularly women presenting with fever of unknown origin, warrant screening for the presence of gas within the bladder. Screening requires not only abdominal $\mathrm{CT}$ but also pelvic $\mathrm{CT}$ in such patients (14).

Emphysematous cystitis therapy involves early and longterm treatment ( 3 to 6 weeks) with broad-spectrum antibiotics such as fluoroquinolones and penicillin in combination with beta-lactamase inhibitors (imipenem, ticarcillin/clavulanate) or third-generation cephalosporins (15). Antifungal agents may used if a fungal infection is reported (22). The bladder should be kept at rest by continuous catheter drainage for a substantial period with the ultimate goal of clearing detectable pathogens in the urine, particularly in patients with urinary retention and neurogenic bladder $(14,18)$. In rare cases, surgery is needed if an abscess develops outside the bladder (11). Delayed diagnosis may lead to unfavorable outcomes, including overwhelming infection, extension to the urethral and renal parenchyma, bladder rupture, and death (23). Early diagnosis and treatment of the primary 


\begin{tabular}{|c|c|c|}
\hline i.v & \multicolumn{2}{|c|}{ 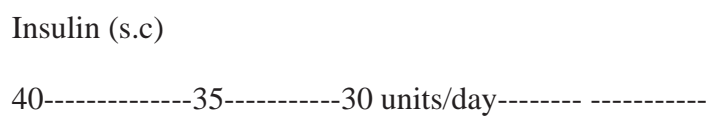 } \\
\hline \multicolumn{2}{|c|}{ imipenem/cilastatin } & pazufloxacin mesilate \\
\hline \multicolumn{3}{|c|}{ Urinary drainage } \\
\hline
\end{tabular}
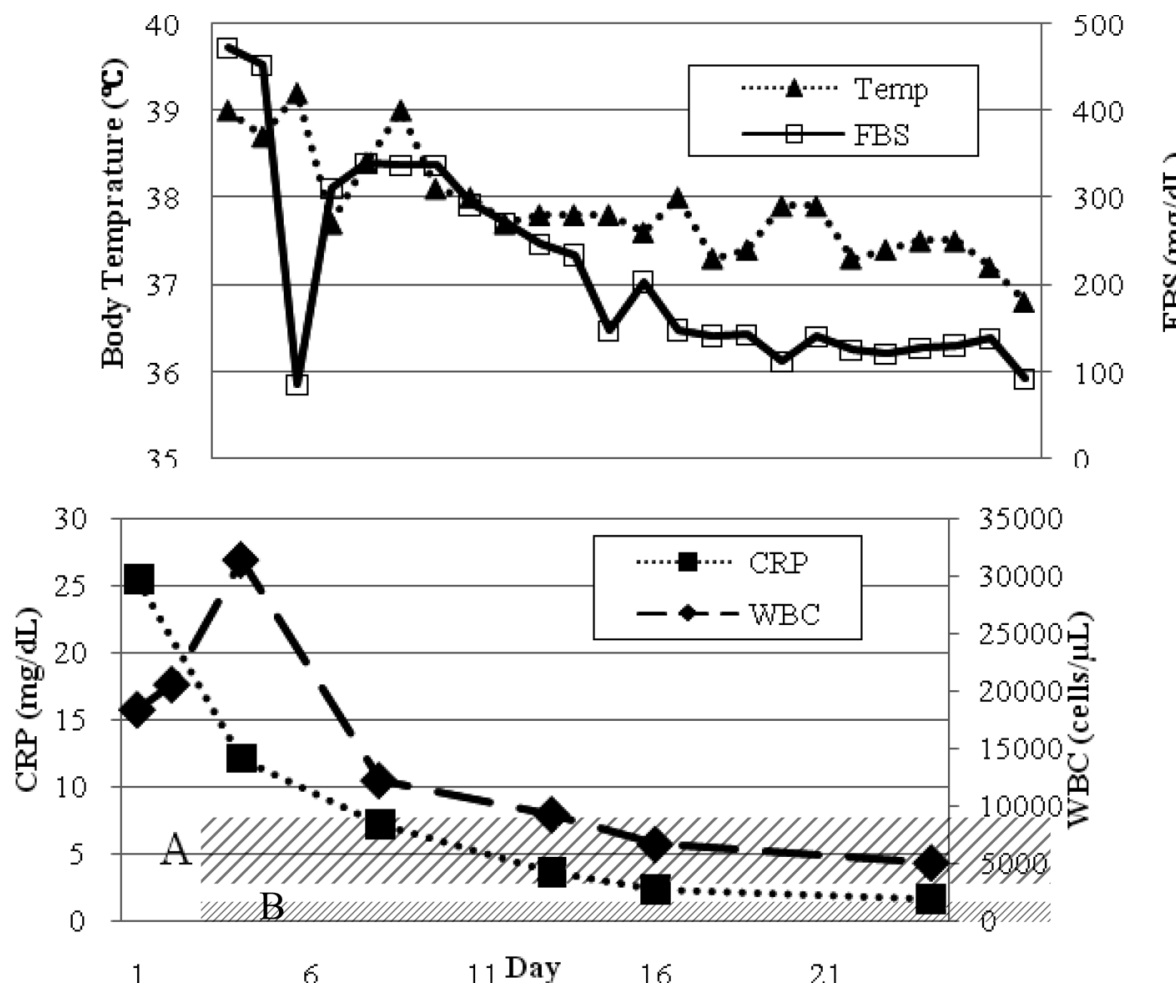

Figure 3. Clinical course after admission. Slanted line site (A) is the normal range of WBC and (B) is the normal range of CRP.

Table 2. Clinical Analysis of 63 Cases of Emphysematous Cystitis in the Japanese Literature

\begin{tabular}{lc}
\hline Mean age (y.o. mean \pm SD) & $71.4 \pm 8.7$ \\
Number (percent of total) & \\
Men & $24(38.1)$ \\
Women & $39(61.9)$ \\
Diabetes mellitus & $41(65.1)$ \\
Neurogenic bladder & $15(23.8)$ \\
Chief complaint & \\
$\quad$ Macrohematuria & $36(57.1)$ \\
$\quad$ Fever & $19(30.2)$ \\
$\quad$ Frequent urination & $7(11.1)$ \\
$\quad$ Ischuria & $6(9.5)$ \\
Complication & \\
$\quad$ Emphysematous pyelonephritis & $3(4.8)$ \\
$\quad$ Septic shock, disseminated intravascular coagulation & $5(7.9)$ \\
Pathogens & \\
$\quad$ E. coli & $28(44.4)$ \\
$\quad$ K. pneumoniae & $17(27.0)$ \\
\hline
\end{tabular}

condition is the key to successful therapy. In addition a strict blood glucose control is important. In the present case it is a reflection point that the patient had an elevated blood glucose level of more than $300 \mathrm{mg} / \mathrm{dL}$ when we changed from a subcutaneous insulin injection therapy to an intravenous injection.
In conclusion, although emphysematous cystitis is a relatively uncommon disease, a high degree of awareness is required for a timely diagnosis and treatment to ensure a good outcome. Treatment with appropriate intravenous antibiotics, urinary drainage, and control of underlying processes such as hyperglycemia are paramount to successful intervention.

\section{References}

1. Harding GK, Zhanel GG, Nicolle LE, Cheang M; Manitoba Diabetes Urinary Tract Infection Study Group. Antimicrobial treatment in diabetic women with asymptomatic bacteriuria. N Engl J Med 347: 1576-1583, 2002.

2. Joseph RC, Amendola MA, Artze ME, et al. Genitourinary tract gas: imaging evaluation. Radiographics 16: 295-308, 1996.

3. Kichikawa S, Samejima T, Itoh T. A case of emphysematous cystitis. Rinsho Hinyokika 60: 679-681, 2006 (in Japanese).

4. Nakano S, Ota S, Hokajima S. A case of emphysematous cystitis. Nichibyorikaishi (Acta Pathologica Japonica) 51: 457, 1962 (in Japanese).

5. Kiyoshima A. Study on cystitis emphysematosa with a case report. Nichihinyokaishi (The Japan Journal of Urology) 57: 1208-1224, 1966 (in Japanese, Abstract in English).

6. Nakayama T, Tohyama Y, Iizumi T, et al. Emphysematous cystitis: a case report. Hinyoukika Kiyo 42: 381-383, 1996 (in Japanese). 
7. Biyani CS, Cornford PA, Scally JS, Powell CS. Emphysematous cystitis. Scand J Urol Nephrol 31: 309-310, 1997.

8. Karashima E, Ejima J, Nakamura H, et al. Emphysematous cystitis with venous bubbles. Intern Med 44: 590-592, 2005.

9. Omerbegovic M. Analysis of heart rate variability and clinical implications. Med Arh 63: 102-105, 2009.

10. Sakamoto F, Taki H, Yamagata T, et al. Emphysematous cystitis with severe hemorrhagic anemia resulting from diabetes mellitus type 2. Intern Med 43: 315-318, 2004.

11. Yung SJ, Shu MC, Jung TS, et al. Unusual gas pattern in emphysematous cystitis: A case report. Kaohsiung J Sci 21: 44-47, 2005.

12. Daya U, Manu J. Emphysematous cystitis and renal stones in cystic fibrosis. JAMA 292: 1953-1954, 2004.

13. Wortmann G, Fleckenstein J. Incidental discovery of emphysematous cystitis. South Med J 91: 785-786, 1998.

14. Yokoo T, Awai T, Yamazaki H, Fukuda Y, Hayashi F, Hosoya T. Emphysematous cystitis complication in a patient undergoing hemodialisis. Clin Exp Nephrol 11: 247-250, 2007.

15. Kumar A, Turney JH, Brownjohn AM, McMahaon MJ. Unusual bacterial infections of the urinary tract in diabetic patients-rare but frequently lethal. Nephrol Dial Transplant 16: 1062-1065, 2001.
16. Taussig AF. Pneumaturia with reported of a case. Boston Med Surg J 156: 769-774, 1907.

17. Bailey H. Cystitis emphysematosa; 19 cases with intraluminal and interstitial collections of gas. Am J Roentgenol Radium Ther Uncl Med 86: 850-862, 1961.

18. Quint HJ, Drach GW, Rappaport WD, et al. Emphysematous cystitis: a review of the spectrum of disease. J Urol 147: 134-137, 1992.

19. Patterson JE, Andriole VT. Bacterial urinary tract infections in diabetes. Infect Dis Clin North Am 11: 735-750, 1997.

20. Holesh S. Gas in the bladder. Cystitis emphysematosa. Clin Radiol 20: 234-236, 1969.

21. Hawtrey CE, Williams JJ, Schmidt JD. Cystitis emphysematosa. Urology 3: 612-614, 1974.

22. Grupper M, Kravtsov A, Potasman I. Emphysematous cystitis: illustrative case report and review of the literature. Medicine 86: 47-58, 2007.

23. Bobba RK, Arsura EL, Sarna PS, et al. Emphysematous cystitis: an unusual disease of the genito-urinary system suspected on imaging. Ann Clin Microbiol Antimicrob 3: 20-24, 2004.

(C) 2010 The Japanese Society of Internal Medicine http://www.naika.or.jp/imindex.html 